\title{
Comparison of inulin with urea as dilutional markers of bronchoalveolar lavage in healthy and heaves-affected horses
}

\author{
Nathalie KIRSCHVInK*, Laurence FIÉveZ, Sophie Dogné, \\ Fabrice Bureau, Tatiana ART, Pierre LEKEUX \\ Laboratory of Functional Investigation, Faculty of Veterinary Medicine, University of Liège, \\ Bât. B 42, Sart Tilman, 4000 Liège, Belgium
}

(Received 5 October 2000; accepted 8 December 2000)

\begin{abstract}
Solute analysis in bronchoalveolar lavage fluid involves the use of dilutional markers to correct for variable recovery of pulmonary epithelial lining fluid (PELF). Urea is the best characterised endogenous marker, whereas inulin appears to meet the requirements of an exogenous marker. In horses, the use of inulin has never been investigated and the impact of lower airway diseases such as heaves, on PELF recovery is unknown. In this study, five healthy and five heaves-affected horses underwent airway endoscopy and bronchoalveolar lavage. PELF recovery from bronchoalveolar lavage was calculated by the inulin and the urea method. The inulin method was compared to the urea method and differences between healthy and heaves-affected horses were analysed. From a technical and analytical point of view, inulin fulfilled the requirements of a marker of dilution as well as urea. When both healthy and heaves-affected horses groups were pooled together, PELF recovery calculated by the inulin method was significantly higher than by the urea method $(6.43 \pm 4.08 \%$ versus $0.789 \pm 0.299 \%, P<$ $0.005)$. No significant differences were observed between healthy and heaves-affected horses, neither by the inulin nor by the urea method. Inulin did not present major advantages over urea, but the combined use of both markers can improve the standardisation of studies comparing PELF compounds, by providing upper limits (inulin dilution) and lower limits (urea dilution) of PELF recovery.
\end{abstract}

inulin / urea / bronchoalveolar lavage / dilution factor

Résumé - Comparaison de l'inuline et de l'urée en tant que marqueurs de dilution de lavage bronchoalvéolaire chez des chevaux sains et des chevaux poussifs. L'analyse des composants du liquide de lavage bronchoalvéolaire implique fréquemment l'utilisation de facteurs de dilution afin de pouvoir corriger la récupération très variable du fluide épithélial pulmonaire (FEP). Parmi les marqueurs utilisés, l'urée est le marqueur endogène le mieux caractérisé, tandis que l'inuline possède toutes les caractéristiques requises d'un marqueur de dilution exogène. L'inuline n'a jamais été

* Correspondence and reprints

Tel.: (32) 436640 30; fax: (32) 436629 35; e-mail: Nathalie.Kirschvink@ulg.ac.be 
étudiée dans l'espèce équine en tant que marqueur de dilution du lavage bronchoalvéolaire. De plus, l'impact des maladies respiratoires pulmonaires, telle que la pousse, sur le taux de récupération du FEP lors de lavage bronchoalvéolaire, n'a pas été étudié dans l'espèce équine. Dans cette étude, cinq chevaux sains et cinq chevaux atteints de pousse ont subi des lavages bronchoalvéolaires au cours d'une endoscopie des voies respiratoires inférieures. La récupération du FEP a été calculée au moyen de la méthode de l'inuline ainsi qu'au moyen de la méthode de l'urée. Les résultats issus des deux techniques ont été comparés, pour les chevaux sains et les chevaux atteints de pousse. D'un point de vue technique et analytique, l'utilisation de l'inuline en tant que facteur de dilution était aussi satisfaisante que celle de l'urée. Lorsqu'il n'y a pas eu de distinction entre les chevaux sains et les chevaux poussifs, le taux de récupération du FEP calculé au moyen de la méthode de l'inuline était significativement plus élevé que celui calculé au moyen de la méthode de l'urée $(6,43 \pm 4,08 \%$ et $0,789 \pm 0,299 \%$ respectivement, $P<0,005)$. Aucune différence significative entre les chevaux sains et les chevaux poussifs n'a été observée, quelle qu'ait été la méthode utilisée. La méthode de l'inuline ne présentait pas d'avantages majeurs comparée à celle de l'urée, mais l'utilisation simultanée des deux méthodes peut néanmoins améliorer la standardisation des études du FEP, en fournissant des limites supérieures (inuline) et inférieures (urée) du taux de récupération du FEP.

inuline / urée / lavage bronchoalvéolaire / facteur de dilution

\section{INTRODUCTION}

In the airways, the pulmonary epithelial lining fluid (PELF) forms an interface between the underlying respiratory tract and the external environment. It contains numerous pulmonary mediators and metabolites, the role of which is often investigated in lower airway disease. Bronchoalveolar lavage is a simple and safe technique for collecting cellular and molecular components from the lung. However, the quantity of PELF washed out of the lung in the return bronchoalveolar lavage fluid (BALF) is unknown and variable [5]. This uncertainty limits the interpretation of measured solute concentrations and complicates comparisons between lavages. Therefore, a marker substance indicating the degree to which PELF has been diluted in the return fluid of bronchoalveolar lavage is useful. Different studies have investigated exogenous and endogenous components as markers of PELF dilution [3, 5-7, 10, 11].

Methylene blue, radioactive tracers ( $99 \mathrm{~m}$ TC-diethylenetriamine pentaacetate, ${ }^{51} \mathrm{Cr}$-EDTA) and inulin have been studied as exogenous markers of BALF dilution [4, $11,14]$. The criteria for an ideal external marker are (1) that the only source of the marker is the instilled lavage fluid, (2) that the marker is inert, (3) that it is not taken up or metabolised by cells, (4) that it does not cross the pulmonary epithelium and (5) that it mixes completely with the PELF in the lavaged lung segment [11]. Methylene blue has been shown to bind to cells or to diffuse into the pulmonary interstitium [3, 10], leading to substantial overestimation of recovered PELF. Moreover, its addition to lavage fluid may strongly interfere with further analysis of BALF compounds. The use of radioactive tracers is often unsuitable for routine use or experimental protocols. Inulin, an inert polysaccharide of high molecular weight ( $5 \mathrm{kDa})$, is not naturally present in the body. Furthermore, it is not absorbed or metabolised by cells, nor does it cross the alveolar epithelium [11]. Finally, it can be easily assayed spectrophotometrically by the method of Roe [13]. Therefore, this compound meets the requirements of an effective external marker [11].

The use of endogenous markers is based on the assumption that their concentrations are uniform throughout the lung, identical in all patients and independent of airway disease. In the special case of urea, it is furthermore presumed that PELF urea concentrations are identical to those in plasma [7]. Determination of these markers in BALF makes it possible to standardise the 
concentrations of PELF within BALF samples. The most commonly used endogenous markers are urea and albumin $[5,7,10,14]$. Sphingomyelin, IgA secretory component, total protein, $\mathrm{Na}^{+}, \mathrm{Cl}^{-}$and $\mathrm{Ca}^{2+}$ have also been investigated $[5,14]$. Among the internal markers, urea is the best known and its validity has been largely investigated [10, 14]. There are some concerns that diffusion of urea from the interstitial fluid into the lavage fluid may occur. The urea influx would lead to an overestimation of PELF recovery. What is referred to as dwell time, i.e. the time lavage fluid remains in the airways before being re-aspirated, is a cornerstone in the standardisation of the bronchoalveolar lavage technique. With increasing dwell time, BALF urea concentration increases and consequently, PELF recovery is overestimated $[6,10]$. Nevertheless, PELF urea concentration has been shown to be independent of lung disease, which is not the case for albumin, whose diffusion rate is increased by airway inflammation [5].

Bronchoalveolar lavage is commonly performed in horses suffering from lower airway disease, especially in horses suffering from heaves [12]. Indeed, research into equine lung disease focuses on inflammatory mediators and other compounds, whose concentration in BALF does not reflect the actual concentration of molecules recovered in PELF. To circumvent this problem, urea and albumin have been proposed as dilutional markers [7], but the above-mentioned concerns regarding these compounds remain for the equine species. Large lavage volumes (100-200 mL) are often used for bronchoalveolar lavage in horses. Therefore, duration of BALF recovery can be variable. This renders standardisation of the dwell time difficult, which limits the accuracy of urea as a dilutional marker. An external marker, whose dilution by PELF is independent of the time lavage fluid remains in the airways, would be more appropriate. Inulin has been shown to be an easy and satisfactory external marker of PELF in humans [11], but has never been tested in horses. Furthermore, it is not known whether lower airway disease has an impact on PELF dilution.

In this protocol, five horses free of airway diseases and five horses with heaves in acute crisis were studied. The aims of our study were: (1) to compare the inulin method to the urea method for the calculation of PELF dilution and (2) to examine whether airway disease has an influence on PELF dilution, calculated either by the inulin or the urea method.

\section{MATERIALS AND METHODS}

The study was approved by the ethical committee of the Faculty of Veterinary Medicine.

\subsection{Horses}

Five healthy horses and five horses with heaves in acute crisis were studied. The healthy animals were chosen on the basis of their age (3-9 years) and the absence of respiratory disorders when bedded on straw and fed hay. The heaves-affected horses were selected on the basis of their history of airway obstruction and their bronchodilatory response to intravenously injected atropine $\left(0.02 \mathrm{mg} \cdot \mathrm{kg}^{-1}\right.$ bodyweight). An acute crisis of heaves was induced by bedding horses on straw and feeding them mouldy hay. The onset of crisis occurred 48 to $72 \mathrm{~h}$ after exposure to hay. Before starting the protocol, all horses underwent pulmonary function tests in order to confirm that they were in the appropriate clinical state.

\subsection{Pulmonary function tests}

Pulmonary function tests consisted in measuring the mechanics of breathing and analysing arterial gas tension. The 
mechanics of breathing required pleural pressure and respiratory airflow measurements. Respiratory airflow and oesophageal pressure were simultaneously measured and total pulmonary resistance $\left(\mathrm{R}_{\mathrm{L}}\right)$, dynamic compliance $\left(\mathrm{C}_{\mathrm{dyn}}\right)$ and maximal pleural pressure changes $(\Delta$ pplmax $)$ were immediately calculated by a computerised system (Ponemah, Gould Instrument Systems, Valley View, OH, USA). The following limits were arbitrarily chosen to control whether the animals were healthy or suffering a crisis of heaves: healthy: $\mathrm{R}_{\mathrm{L}} \leq 0.10 \mathrm{kPa} \cdot \mathrm{s} \cdot \mathrm{L}^{-1}$, $\mathrm{C}_{\text {dyn }} \geq 10 \mathrm{~L} \cdot \mathrm{kPa}^{-1}, \Delta$ pplmax $\leq 1.00 \mathrm{kPa}$; suffering a crisis of heave : $\mathrm{R}_{\mathrm{L}} \geq$ $0.25 \mathrm{kPa} \cdot \mathrm{s} \cdot \mathrm{L}^{-1}, \mathrm{C}_{\text {dyn }} \leq 10 \mathrm{~L} \cdot \mathrm{kPa}^{-1}, \Delta$ pplmax $\geq 2.50 \mathrm{kPa}$. Further details about the measurement technique are reported elsewhere [1].

Arterial blood was withdrawn anaerobically by puncture of Arteria carotis communis and analysed, after correction for body temperature, for partial pressure in $\mathrm{O}_{2}$ (AVL 995, VEL, Leuven, Belgium). $\mathrm{PaO}_{2}$ $\geq 90 \mathrm{mmHg}$ was considered to be acceptable in healthy horses and $\mathrm{PaO}_{2} \leq 80 \mathrm{mmHg}$ was required for horses suffering a crisis.

Results of the pulmonary function tests are reported in Table I.

\subsection{Airway endoscopy and bronchoalveolar lavage}

Endoscopy of the airways and bronchoalveolar lavage were performed on the sedated horse (Sedivet $^{\circledR}$, Boehringer Ingelheim, Ingelheim, Germany, romifidine,
$0.01 \mathrm{mg} \cdot \mathrm{kg}^{-1}$ bodyweight intravenously). A fibreoptic endoscope $(250 \mathrm{~cm}$ in length, $9 \mathrm{~mm}$ in diameter) (Pentax, Breda, The Netherlands) was wedged into the locally anaesthetised bronchi, and previously prepared saline containing $0.5 \mathrm{mg} \cdot \mathrm{mL}^{-1}$ inulin was instilled in situ. The procedure was standardised by injecting a $60 \mathrm{~mL}$ aliquot of prepared saline into the bronchi and collecting it as soon as the instillation was performed (dwell time $<15 \mathrm{~s}$ ). Three consecutive instillations were performed at the same site. There was no possibility of measuring the applied negative pressure for fluid aspiration, but a single operator performed all lavages and attempted to standardise the aspiration procedure. The lavage was considered successful when alveolar surfactant and more than $60 \%$ of saline were aspirated. BALF was pooled, immediately cooled on ice and processed for definitive storage until analysis (see processing description below).

\subsection{Saline preparation \\ for bronchoalveolar lavage and inulin standard dilutions}

Saline $(0.9 \% \mathrm{NaCl})$ was heated at $37^{\circ} \mathrm{C}$ in a water bath and inulin was added in order to obtain an initial inulin concentration of $0.5 \mathrm{mg} \cdot \mathrm{mL}^{-1}$ saline. Heating was necessary for the successful dissolution of inulin. Five samples of prepared saline were stored at $-80{ }^{\circ} \mathrm{C}$ for determination of initial inulin concentration. On the same occasion, dilutions for a standard curve were prepared (dilution of 1.000, 0.900, 0.810, 0.729, 0.656

Table I. Pulmonary function tests. Values are presented as means \pm SD.

\begin{tabular}{lccc}
\hline Variable & Unit & $\begin{array}{c}\text { Healthy horses } \\
(n=5)\end{array}$ & $\begin{array}{c}\text { Heaves-affected horses } \\
(n=5)\end{array}$ \\
\hline $\mathrm{R}_{\mathrm{L}}$ & $\mathrm{kPa} \cdot \mathrm{s}^{\mathrm{L}} \mathrm{L}^{-1}$ & $0.07 \pm 0.01$ & $0.28 \pm 0.06^{*}$ \\
$\mathrm{C}_{\mathrm{dyn}}$ & $\mathrm{L} \cdot \mathrm{kPa}$ & $17.9 \pm 6.2$ & $5.8 \pm 1.9 *$ \\
$\Delta \mathrm{pplmax}$ & $\mathrm{kPa}$ & $0.66 \pm 0.32$ & $3.33 \pm 0.82^{*}$ \\
$\mathrm{PaO}_{2}$ & $\mathrm{mmHg}$ & $98.8 \pm 7.9$ & $71.3 \pm 4.5^{*}$
\end{tabular}

* Significantly different from healthy horses, $P<0.05$. 
and 0.590 of the initial solution) and equally stored at $-80{ }^{\circ} \mathrm{C}$ until use.

\subsection{Bronchoalveolar lavage fluid treatment}

Recovered bronchoalveolar lavage fluid (BALF) was divided into two portions, for inulin and urea, respectively. The first portion was centrifuged at $400 \times g$ for $10 \mathrm{~min}$ and the supernatant was withdrawn and stored at $-80{ }^{\circ} \mathrm{C}$ for later inulin determination. Three samples were stored for each horse. The second portion was aliquoted into three samples and stored at $-80{ }^{\circ} \mathrm{C}$ for urea analysis.

\subsection{Plasma treatment for urea determination}

Immediately after bronchoalveolar lavage, venous blood was sampled by jugular puncture and heparinised. After centrifugation $(10 \mathrm{~min}, 900 \times g)$, plasma was withdrawn and aliquoted into $1 \mathrm{~mL}$ samples. Subsequently, aliquots were stored at $-80{ }^{\circ} \mathrm{C}$ until urea analysis.

\subsection{Inulin assay}

A spectrophotometric assay was performed as described by Restrick et al. [11]. Briefly, $200 \mu \mathrm{L}$ of defrosted BALF or of standard solution and its dilutions were added to $800 \mu \mathrm{L}$ of $5 \%$ perchloric acid (PCA, Merck, Darmstadt, Germany), $500 \mu \mathrm{L}$ of $0.09 \mathrm{M}$ resorcinol (Fluka, Buchs, Switzerland) in $95 \%$ ethanol and $1500 \mu \mathrm{L}$ of $30 \%$ hypochloric acid ( $\mathrm{HCl}$, Merck, Darmstadt, Germany). All samples and standards were duplicated. The mixture was prepared in $4 \mathrm{~mL}$ plastic tubes (Greiner, Frickenhausen, Germany) and vortex-mixed before being heated at $80{ }^{\circ} \mathrm{C}$ for one hour in a water bath. Tubes were removed from the water bath and cooled down to ambient temperature.
Absorbances of $1 \mathrm{~mL}$ aliquots were read at $413 \mathrm{~nm}$ using a spectrophotometer (Camspec M302, Cambridge, UK) and $4.5 \mathrm{~mL}$ cuvettes (Dispolab Kartell, Italy). A standard curve was plotted, and the inulin concentration was determined from the absorbance of each BALF sample. All assays and consequent calculations were performed on four occasions. The intraassay and inter-assay coefficients of variation were 7.8 and $7.5 \%$, respectively.

\subsection{Urea assay}

Plasma urea was determined by using the spectrophotometric BUN-Endpoint 20 kit (Sigma Diagnostics, St. Louis, MO, USA). The recommended instructions were slightly modified for better precision in horse plasma. The samples were defrosted and vortex-mixed. Preliminary assays had shown that better accuracy and repeatability of analysis were achieved by PCA-induced deproteinisation. Therefore, $250 \mu \mathrm{L}$ of plasma were added to $750 \mu \mathrm{L}$ of $5 \%$ PCA (perchloric acid, Merck, Darmstadt, Germany). PCA and plasma were vortex-mixed and centrifuged for $2 \mathrm{~min}$ at $900 \times g$. Supernatant was used for the urea assay. One vial of reagent was prepared with $25 \mathrm{~mL}$ distilled water (instead of $20 \mathrm{~mL}$, as suggested by the manufacturer). Ten microliters (instead of $5 \mu \mathrm{L}$, as suggested by the manufacturer) of plasma-PCA supernatant were mixed to $500 \mu \mathrm{L}$ of reagent and incubated for $10 \mathrm{~min}$. The assay was prepared in $1 \mathrm{~mL}$ cuvettes (Dispolab Kartell, Italy) and absorbance was read at $340 \mathrm{~nm}$ by a spectrophotometer (Camspec M302, Cambridge, UK). Plasma urea concentration data were calculated as recommended by the supplier, but taking into account the dilution by PCA (1:4). The intra- and inter-assay coefficient of variation of this method was $<5 \%$.

For BALF urea determination, the method described by Rennard et al. [10] was applied. The BUN-Endpoint 20 kit (Sigma Diagnostics, St. Louis, MO, USA) 
was used. One vial of reagent was prepared with $20 \mathrm{~mL}$ water. BALF was defrosted and centrifuged for $2 \mathrm{~min}$ at $900 \times g$. Two hundred-fifty microliters of BALF supernatant were added to $500 \mu \mathrm{L}$ reagent. After $10 \mathrm{~min}$ of incubation, absorbance was read at $340 \mathrm{~nm}$. A saline blank allowed the correction of reagent dilution due to the sample. A further blank with lavage fluid alone was also prepared to correct for optical absorbance of the sample. After this modification, the coefficient of variation of the assay was $<5 \%$ intra-assay and $<10 \%$ interassay. All plasma and BALF samples were assayed on two occasions.

\subsection{Dilution factor calculations}

\subsubsection{Inulin dilution factor (Inu DF) and proportion of PELF in BALF} (for details see Restrick et al. [11])

The concentration of inulin in BALF expressed as the fraction of the concentration of inulin in the instilled fluid is the dilution factor (Inu DF):

$$
\mathrm{InuDF}=\frac{\text { Concentrationofinulin in } \mathrm{BALF}\left(\mathrm{mg} \cdot \mathrm{mL}^{-1}\right)}{\text { Concentrationof inulin in instilledfluid }\left(\mathrm{mg} \cdot \mathrm{mL}^{-1}\right)} .
$$

Hence,

$$
\begin{gathered}
\text { Volume of PELF }(\mathrm{mL})=[1-\mathrm{Inu} \mathrm{DF}] \times \\
\text { Volume BALF }(\mathrm{mL}) .
\end{gathered}
$$

The proportion of PELF in BALF is therefore:

$$
\frac{\text { Volume of PELF }(\mathrm{mL})}{\text { Volume of BALF }(\mathrm{mL})}=1-\text { Inu DF. }
$$

\subsubsection{Urea dilution factor (Ur DF) and proportion of $P E L F$ in $B A L F$ (for details see Rennard et al. [10])}

Based on the assumption that

$$
\text { Urea }_{[\text {PELF] }}=\text { Urea }_{[\text {plasma }}
$$

and the following equation calculating urea dilution factor of BALF:

$$
\mathrm{UrDF}=\frac{\text { BALF urea }\left(\mathrm{mmol} \cdot \mathrm{L}^{-1}\right)}{\text { plasma urea }\left(\mathrm{mmol} \cdot \mathrm{L}^{-1}\right)}
$$

the proportion of PELF in BALF equals:

$$
\frac{\text { Volume of PELF }(\mathrm{mL})}{\text { Volume of BALF }(\mathrm{mL})}=\mathrm{Ur} \mathrm{DF} \text {. }
$$

\subsection{Statistical evaluation}

Results of pulmonary function tests are expressed as mean \pm standard deviation (SD). All results dealing with analysis of urea and inulin are presented as mean \pm standard error of mean (SEM). Data were compared by one-way ANOVA and correlation analyses were performed by simple regression. $P<0.05$ was chosen as the level of significance.

\section{RESULTS}

\subsection{Inulin assay}

Over the range of concentrations assayed, absorbance was a linear function of inulin concentration. The inulin dilution factor (Inu DF) of healthy horses ranged from 0.863 to 0.985 (mean \pm SEM, $0.934 \pm 0.044$ ) and those of horses with heaves ranged from 0.882 to 0.982 (mean \pm SEM, $0.937 \pm$ $0.037)$. Individual results are reported in Table II. The percentage of PELF in BALF calculated by the Inu DF ranged from 1.47 to $13.71 \%$ (mean \pm SEM, $6.61 \pm 2.42 \%$ ) in healthy horses and from 1.78 to $11.77 \%$ (mean \pm SEM, $6.25 \pm 1.95 \%$ ) in heavesaffected horses. The difference between groups was not significant.

\subsection{Urea assay}

Plasma urea concentrations of healthy and heaves-affected horses ranged from 5.06 
Table II. Inulin and urea dilution factors and respective PELF percentages.

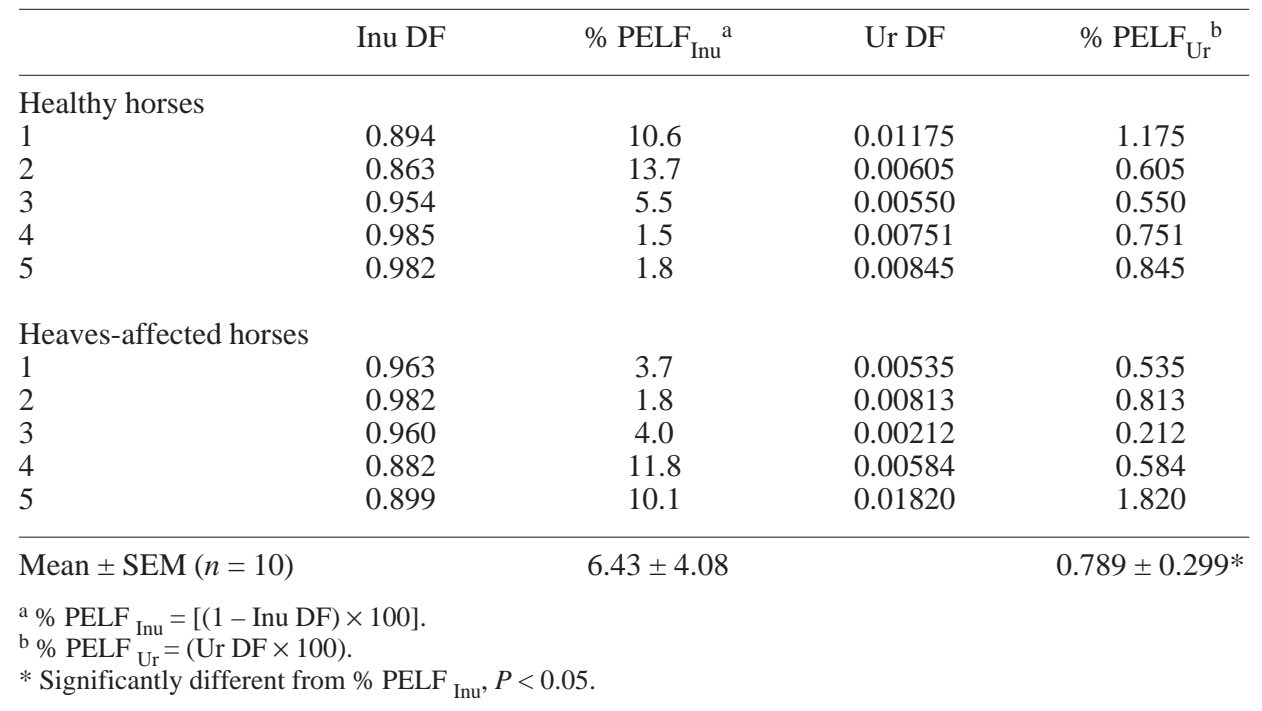

to $9.70 \mathrm{mmol} \cdot \mathrm{L}^{-1}($ mean $\pm \mathrm{SEM}, 7.72 \pm$ $\left.0.81 \mathrm{mmol} \cdot \mathrm{L}^{-1}\right)$. BALF urea concentrations of both groups ranged from 0.021 to $0.133 \mathrm{mmol} \cdot \mathrm{L}^{-1}($ mean $\pm \mathrm{SEM}, 0.059 \pm$ $\left.0.019 \mathrm{mmol} \cdot \mathrm{L}^{-1}\right)$. The individual Ur DF are shown in Table II. The percentage of PELF in BALF calculated by the urea dilution factor in healthy horses ranged from 0.550 to $1.175 \%$ (mean \pm SEM, $0.785 \pm 0.180 \%$ ) and in heaves-affected horses from 0.212 to $1.820 \%$ (mean \pm SEM, $0.793 \pm 0.419 \%$ ). There was no significant difference between groups. Linear regression between plasma urea and BALF urea was not significant, neither for all individuals taken together, nor after dividing them into healthy and heaves-affected groups.

\subsection{Comparison of inulin dilution factors with urea dilution factors}

The percentage of PELF in BALF was significantly higher when calculated by Inu DF than by Ur DF $(n=10, P<0.005)$ (Tab. II). Because of the widespread Inu DF values, the difference between Inu DF and Ur DF was no more significant when calculated separately for healthy horses $(P=0.074)$ and heaves-affected horses $(P=0.056)$ (Fig. 1). The correlation between the inulin-calculated PELF $\%$ and the ureacalculated PELF \% was not significant $(r=$ 0.157, $P=0.665$ ) (Fig. 2).

\section{DISCUSSION}

In this study, inulin and urea, two dilutional markers of PELF recovered by bronchoalveolar lavage, were analysed in healthy and heaves-affected horses. Moreover, this was aimed at comparing inulin with urea and evaluating the impact of airway disease on the dilution of PELF.

\subsection{Inulin as a dilutional marker}

Inulin appears to meet the theoretical criteria of an exogenous marker of dilution of BALF. It is not naturally present in the body, is inert, and does not cross the pulmonary barrier. Normand et al. [9] demonstrated that in the lungs of foetal lambs, alveolar epithelium is impermeable to radiolabelled 


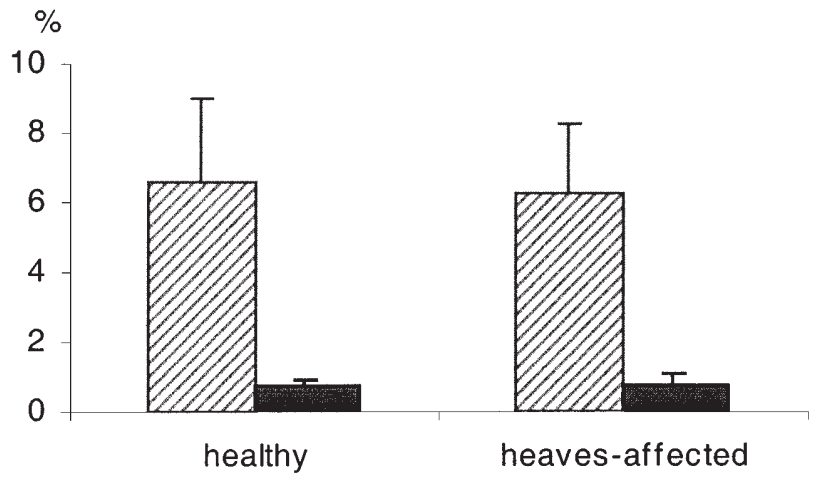

WIA PELF/BALF percentage calculated by the inulin method

PELF/BALF percentage calculated by the urea method
Figure 1. Percentage of PELF in BALF in healthy and heaves-affected horses. Data are presented as mean \pm SEM.

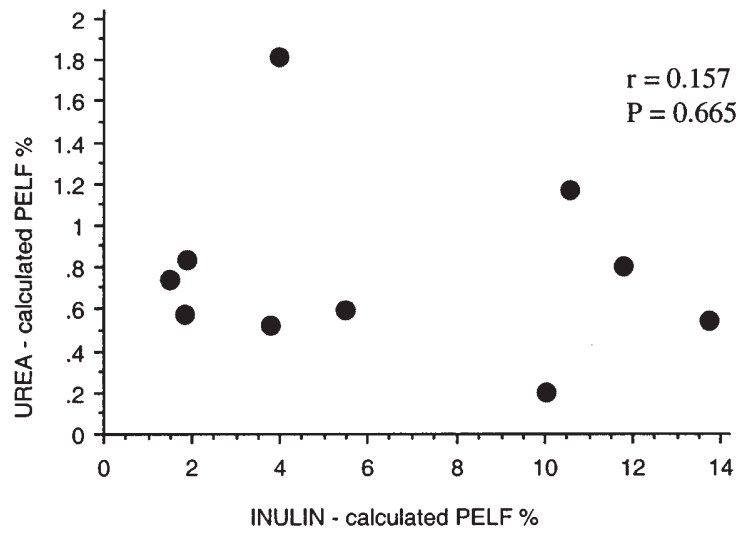

Figure 2. Correlation between proportion of PELF in BALF calculated by the inulin ( $x$-axis) and the urea ( $y$-axis) method.

inulin, either administered intravenously or instilled directly into the alveoli. Furthermore, inulin has no effect on cell viability [11], which can be of major importance in some fields of lung research. The use of inulin in practice and in research could be considered, because neither the preparation of lavage solution nor the consecutive lavage processing requires sophisticated equipment or knowledge. In fact, after lavage processing, samples could be stored at $-80{ }^{\circ} \mathrm{C}$ and were analysed several weeks after the investigation. The assay procedure itself was easy and rapid, with satisfactory coefficients of intra- and inter-variation (7.8 and $7.5 \%$, respectively). Our results are in line with those of Restrick et al. [11]. They used inulin as a dilutional marker in healthy and asthmatic humans. The dilution factors (DF) they reported were similar to those in our study. These investigators did not observe a significant difference between the DF calculated in control patients and those in asthmatics. Our data support this, as we found similar DF in healthy and heaves-affected horses. Inulin has also been used as an exogenous marker in nasal lavages in children [2] and in bronchoalveolar lavages in dogs [3] and rats [14]. The initial concentration of instilled inulin used in the latter 
study was much higher $\left(3 \mathrm{mg} \cdot \mathrm{mL}^{-1}\right.$ instead of $\left.0.5 \mathrm{mg} \cdot \mathrm{mL}^{-1}\right)$, so that these results could not be reliably compared with our data.

\subsection{Urea as a dilutional marker}

Urea is the most commonly used endogenous marker for calculations of PELF dilution. The major advantage is that no preparation of instillation fluid is necessary for its use and that lavage processing is even more simple than for inulin. By contrast, this procedure requires blood sampling and consecutive centrifugation for the preparation of plasma aliquots. The samples could be stored at $-80^{\circ} \mathrm{C}$ until analysis. The coefficient of variation of the urea assay was also satisfactory (5\% intra- and $10 \%$ interassay). Our results were in agreement with those of previous studies performed in horses [7, 8] and humans [5, 10]. We did not find any difference in DF by comparing healthy to heaves-affected horses. In healthy and lung-diseased infants, urea is the dilutional marker which best standardises the lavage concentrations, independently of lung status [5]. There are concerns that diffusion of urea into the lavage fluid from the pulmonary epithelium may occur during lavage and that epithelial lesions can increase urea influx, in such a way that PELF recovery is selectively overestimated in patients with lung disease [5]. Regarding these concerns, the standardisation of the sampling technique appears to be of major importance. Similar instilled fluid volumes, dwell times and applied negative pressures for the aspiration of lavage fluid should be respected in order to reduce, or at least to standardise, urea influx and epithelial lesion due to the endoscope wedged in the bronchi.

\subsection{Comparison of inulin with urea as dilutional markers}

As illustrated in Figure 1, the percentage of PELF in BALF fluid was higher when calculated by the inulin method than by the urea method. The difference between the techniques was significant when all horses, healthy and heaves-affected, were considered $(n=10)$. The lack of significance within the healthy and heaves-affected groups was due to the small number of individuals $(n=5)$ and the widespread range of results. The regression analysis revealed a weak correlation between the PELF/BALF percentages calculated by both methods (Fig. 2). To the authors' knowledge, no information about the simultaneous use of inulin and urea as dilutional markers has been published. The problem of both techniques lies in the fact that the modifications of marker concentration are nearly negligible, because of the enormous dilution of PELF $[5,10,11]$. In the case of inulin, the dilution of the instilled fluid by PELF is minimal, whereas the increase of urea in recovered lavage fluid is also minimal. Therefore, both techniques need to be very sensitive. A real validation of the inulin method by the urea method or vice versa is not possible, as no reference method exists. Despite these limitations, in their inulinstudy Restrick et al. [11] strongly recommended the use of inulin and urea as markers. Indeed, by using inulin as an external marker, neither "contamination" due to marker influx nor marker loss due to epithelial crossing may occur. But incomplete mixing of lavage fluid with PELF can lead to inaccurate sampling. In the case of inulin, large lavage samples and long dwell times seem to be recommended. The opposite is true if urea is used as an endogenous marker. In fact, urea cannot be "lost" by incomplete lavage mixing, but can be highly diluted. Nevertheless, large lavage volumes and long dwell times favour urea influx and overestimation of PELF recovery. The combined use of an external marker of dilution (e.g., inulin) and an internal marker (e.g., urea) may allow more accurate determination of PELF, providing an upper and lower limit, respectively, of the proportion of PELF sampled in BALF. A high discrepancy between 
the results obtained by both methods would either indicate that incomplete PELF-lavage mixing occurred during bronchoalveolar lavage, or that large lavage fluid volumes and/or increased dwell time allowed urea influx into lavage fluid. In the case of an incomplete PELF-lavage fluid mixing, the Ur DF may be diminished to a larger extent than the Inu DF, which would lead to a higher PELF recovery calculated by the Inu DF than by the Ur DF. In the case of large lavage volumes, which are often combined with increased dwell times, the urea influx may be proportionally higher than the inulin dilution. Consequently, the urea PELF recovery would be increased to a higher extent than the inulin recovery. Further studies testing these hypotheses by assessing the impact of lavage volume and dwell time on the Inu DF and the Ur DF would be interesting. The establishment of "acceptable" discrepancy values between both methods should also be attempted.

In conclusion, we have shown that inulin and urea are valid dilutional markers of BALF in horses and that recovery of PELF is independent from lung disease. There was no significant correlation between both methods, but their combined use may provide information about the quality of fluid mixing during bronchoalveolar lavage.

\section{ACKNOWLEDGMENTS}

The authors would like to thank Carine Gresse for technical assistance and Martine Leblond for typing the manuscript. Nathalie Kirschvink and Laurence Fiévez are both Ph.D. students supported by grants of the Fund for Research in Industry and Agriculture (FRIA), Brussels, Belgium. Fabrice Bureau is a research fellow of the National Fund for Scientific Research (FNRS), Brussels, Belgium.

\section{REFERENCES}

[1] Art T., Duvivier D.H., Votion D., Anciaux N., Vandenput S., Bayly W.M., Lekeux P., Does an acute COPD crisis modify the cardiorespiratory and ventilatory adjustments to exercise in horses?, J. Appl. Physiol. 84 (1998) 845-852.

[2] Balfour-Lynn I.M., Valman B., Silverman M., Webster A.D.B., Nasal IgA response in wheezy infants, Arch. Dis. Child 68 (1993) 472-476.

[3] Baughman R.P., Bosken C.H., Loudon R.G., Hurtubise P., Wesseler T., Quantitation of bronchoalveolar lavage with methylene blue, Am. Rev. Respir. Dis. 128 (1983) 266-270.

[4] Bayat S., Menaouar A., Anglade D., Ettinger H., François-Joubert A., Benchetrit G., Grimbert F.A., In vivo quantitation of epithelial lining fluid in dog lung, Am. J. Respir. Crit. Care Med. 158 (1998) 1715-1723.

[5] Dargaville P.A., South M., Vervaart P., McDougall P., Validity of markers of dilution in small volume lung lavage, Am. J. Respir. Crit. Care Med. 160 (1999) 778-784.

[6] Marcy T.W., Merrill W.W., Rankin J.A., Reynolds H.Y., Limitations of using urea to quantify epithelial lining fluid recovered by bronchoalveolar lavage, Am. Rev. Respir. Dis. 135 (1987) 1276-1280.

[7] McGorum B.C., Dixon P.M., Halliwell R.E.W., Irnving P., Evaluation of urea and albumen as endogenous marker of dilution of equine bronchoalveolar lavage fluid, Res. Vet. Sci. 55 (1993) 52-56.

[8] Mills P.C., Roberts C.A., Smith N.C., Effects of ozone and airway inflammation on glutathione status and iron homeostasis in the lungs of horses, Am. J. Vet. Res. 57 (1996) 1359-1363.

[9] Normand I.C., Olver R.E., Reynolds E.O.R., Strang L.B., Permeability of lung capillaries and alveoli to non-electrolytes in the foetal lamb, J. Physiol. 219 (1971) 303-330.

[10] Rennard S.I., Basset G., Lecossier D., O'Donnell K.M., Pinkston P., Martin P.G., Crystal R.G., Estimation of volume of epithelial lining fluid recovered by lavage using urea as marker of dilution, J. Appl. Physiol. 60 (1986) 532-538.

[11] Restrick L., Sampson A.P., Piper P.J., Costello J.F., Inulin as a marker of dilution of bronchoalveolar lavage in asthmatic and normal subjects, Am. J. Respir. Crit. Care Med. 151 (1995) 1211-1217.

[12] Robinson N.E., Derksen F.J., Olszewski M.A., Buechner-Maxwell V.A., The pathogenesis of chronic obstructive pulmonary disease of horses, Br. Vet. J. 152 (1996) 283-305.

[13] Roe J.H., A colorimetric method for the determination of fructose in blood and urine, J. Biol. Chem. 107 (1934) 15-22.

[14] Von Wichert P., Joseph K., Müller B., Frank W.M., Bronchoalveolar lavage: Quantitation of intraalveolar fluid?, Am. Rev. Respir. Dis. 147 (1993) 148-152. 